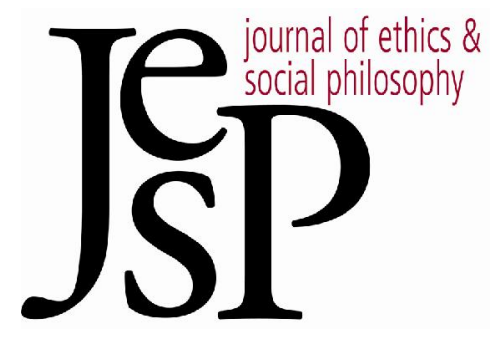

\title{
INSTRUMENTAL MYTHOLOGY
}

BY MARK SCHROEDER

Journal of Ethics\& Social Philosophy

SYMPOSIUM I | DECEMBER 2005

URL: WWW.JESP.ORG

COPYRIGHT @ MARK SCHROEDER 2005 


\title{
INST RUMENTAL MYTHOLOGY
}

\author{
By Mark Schroeder
}

\begin{abstract}
MONG StandaRD Views about instrumental reasons and rationality, 1 as Joseph Raz reminds us, is "an ambitious claim, namely that all rea11 sons are instrumental." 1 So far from this being true, Raz claims, no reasons are instrumental, at least in a way that has anything to do with ends. The idea that there are is, as Raz provocatively puts his thesis, a myth. Central to Raz's argument, as to most philosophical discussions of instrumental reason, is the question of whether the following schema is valid:
\end{abstract}

Schema Detach: For all agents $\mathrm{x}$ and act-types $\mathrm{m}$, if $\mathrm{x}$ has end $\mathrm{E}$ and $\mathrm{m}$ is a necessary means for $\mathrm{x}$ to accomplish $\mathrm{E}$, then there is a reason for $x$ to do $m$.

If Schema D etach is valid, then in virtue of having an end, you have reasons to take the means to that end. Raz, and most contemporary theorists about instrumental reason, take it as obvious that Schema Detach is not valid, and as a constraint on an adequate account of instrumental reason, that it not validate Schema D etach.2

The central piece of argument in Raz's rich and interesting article, "The Myth of Instrumental Rationality," is to show that given a natural view about the entailment relation between reasons, the standard, "Wide Scope," way of invalidating Schema Detach does not work. This motivates his own account of instrumental irrationality as a kind of failure of proper functioning, which he argues succeeds at invalidating Schema D etach where this account fails. If Raz's account is right, then there is no distinctive domain of instrumental reasons, because there are no reasons that are specifically explained by ends.

This makes it sound as though Raz is advancing a new or deep argument against the view that there is a distinctive domain of instrumental reasons or rationality, and for the view that instrumental reasons and rationality are a myth: "It appears," he begins to conclude on page 26, "that there is no such thing as instrumental rationality." But this, I think, gets the dialectic the wrong way around. The structure of Raz's paper is really that of a defensive action. It doesn't follow so much from Raz's distinctive positive view that there are no distinctively instrumental reasons, as from the denial that Schema D etach is valid, all by itself. If ends don't give rise to reasons, then there are no reasons that arise from ends, and hence no instrumental reasons. But this is something he assumes with very little distinctive argument. For

1 Raz [2005, 2].

2 Raz cites Bratman [1987], Korsgaard [1997], Broome [1999], [2000] and Wallace [2001]. 
most of the paper, he isn't out to argue that instrumental reasons are a myth, so much as to defend this view, in the face of difficulties he himself raises.

If Raz is right that the ordinary way of invalidating Schema D etach doesn't work, then the idea that Schema D etach is invalid, and hence the idea that there are no instrumental reasons, is in serious trouble and in need of such a defense. In fact, I'll argue here that Raz's view does no better at invalidating Schema D etach than do the standard views that he criticizes. And that, I think, should make us question whether Schema Detach might not, after all, be valid. I'll explain why we should find Raz's - the standard - argument that it is not valid suspicious, and close by summarizing some of the reasons to think that it is valid. And if Schema Detach does turn out to be valid, then instrumental reasons are alive and healthy, after all.

\section{Wide-Scoping and the Facilitative Principle}

The standard contemporary account of instrumental reason is W ide Scoping. Wide Scopers are so called, because their view is modeled on ${ }^{3}$ the idea that "ought" and "reason" are propositional operators, and hence that standard formulations of hypothetical imperatives like "If you have the end, you ought to [have a reason to] take the means" are scopeambiguous. For since "ought" ["reason"] appears both in the consequent and in the sentence as a whole, both seem like they could be candidates for the proposition which it takes as its scope. On a C onsequent-Scope view, where it takes the consequent as its scope, Schema Detach is validated. But on a Wide-Scope view, where it takes the whole sentence as its scope, Schema Detach is supposed to be invalidated. 4

The reason this is thought to be true is that it is held that Wide $\mathbf{0}$ does not entail Consequent $\mathbf{O}$, and consequently that Wide $\mathbf{R}$ should not entail Consequent R:

Wide 0:

Consequent 0:
$\mathrm{O}$ (If have end $\mathrm{E}$, then take means $\mathrm{M}$ to $\mathrm{E})^{5}$

If have end $\mathrm{E}$, then $\mathrm{O}$ (take means $\mathrm{M}$ to $\mathrm{E}$ )

\footnotetext{
3 But not committed to, except in virtue of some versions of the argument for Wide Scoping. See Schroeder [2004].

4 See, for example, Hill [1973], Greenspan [1975], Darwall [1983], G ensler [1985], Korsgaard [1997], Hampton [1998], Broome [1999] and Wallace [2001].

5 For notational convenience, I here suppress reference to the agent in the formulation of these principles. " $\mathrm{O}$ " denotes the "ought" operator, and " $\mathrm{R}$ " denotes the "reason" operator. Of course I don't, in fact, endorse the view that either is really a propositional operator, or even an agent-indexed propositional operator. Each, in my view, expresses a relation between agents and action-types. I use the assumption for notational convenience. For Wide Scope views that get around this by using disjunctive formulations, see Hill [1973] and D arwall [1983].
} 
Wide R: $\quad$ R(If have end $\mathrm{E}$, then take means $\mathrm{M}$ to $\mathrm{E}$ )

Consequent R: If have end $\mathrm{E}$, then $\mathrm{R}$ (take means $\mathrm{M}$ to $\mathrm{E}$ )

The non-entailment of Consequent $\mathbf{0}$ by Wide $\mathbf{0}$ follows from a natural view about the entailment relations between ought claims. This view is that oughts transfer to conditions that are neessary, but not to conditions that are merely sufficient. So if you ought to buy a gallon of milk, and there is only one brand of milk available, brand A, then you ought to buy brand A . But if instead there are two brands available, it neither follows that you ought to buy brand A nor that you ought to buy brand B. It only follows that you ought to buy one or the other. So when discussions of instrumental reason only included discussion of what the agent ought to do, it was natural to think that Wide Scope accounts invalidated the "ought" analogue of Schema Detach, since there seem to be two ways of complying with Wide 0 , just as there are two brands of milk.

But Raz argues, plausibly, that reasons are different from oughts. According to Raz, if there is a reason for you to buy a gallon of milk, and there are two brands available, then there is a reason for you to buy brand $\mathrm{A}$ and a reason for you to buy brand $B$ - there is simply no further reason for you to buy both. So Raz holds that the right account of the entailments among reasons, which he calls the Facilitative Principle, yields the result that a Wide Scope account of instrumental reason does validate Schema D etach. For it is just like the case of the gallon of milk. Since reasons are not like oughts, the fact that there are two ways to comply with your reason to ensure that you either take the means to your end or don't have that end does not preclude there following reasons to do each. So on Raz's view, if Wide Scopers are right that there is a reason for everyone to either take the means to her ends or not have those ends, then anyone who has an end does have a reason to take the means.

This is, of course, not a dialectically powerful argument against Wide Scoping. Wide Scopers obviously think that Raz is wrong about the entailment relations among reasons. So at best it is an argument that Wide Scopers are committed to some unintuitive implications in their view about this. But it is still a serious challenge. Wide Scopers' discussions seem to have taken for granted that the entailment relations among reasons will be the same as those for oughts. And Raz has suggested, plausibly, that they are not. It is a challenge Wide Scopers need to answer.

I am not going to argue either for or against Raz's view about the Facilitative Principle - his view that the entailments among reasons are different than those among oughts. I think it is natural and plausible, even though we have to be comfortable with just a little bit of metaphysics before we can be 
comfortable about its consequences. ${ }^{6}$ What I will instead suggest, is that if it is right, then Raz's positive view does not succeed at invalidating Schema D etach, either. And, if that is so, it should make us suspicious of why invalidating Schema D etach is such a good constraint on an account of instrumental reason in the first place. I'll argue in sections 3 and 4 that it is not.

\section{Raz's Positive View and Detaching}

According to Raz's positive view, what goes amiss when an agent has an end and does not take the necessary means to it is not that there is a reason not to do this which the agent flouts, but that this constitutes a failure in proper functioning:

People who fail to take the means to their ends display or manifest a form of malfunctioning criticisable as a form of irrationality [19].

The source of our sense that something there is irrational is not that the irrational agent's beliefs or actions are undesirable. It is that he is not functioning properly... there is an ideal of rational agency, which that agent failed to reach on that occasion [18].

According to Raz, some ways of functioning as an agent are non-ideal or improper, but not because there are reasons not to function in these ways. So his account doesn't appeal to reasons in order to explain what is going on in the domain of instrumental reason. And since it doesn't appeal to reasons, he does not appeal to any Wide-Scope reason to either take the means to your ends or not have those ends, of the kind the Wide Scoper believes in, to entail a reason to take the means by way of the Facilitative Principle. This is what makes Raz believe that he at least stands in a better position than Wide Scopers to avoid validating Schema D etach.

But Raz still acknowledges that there is something further to be said, and devotes part of section 2 and all of section 3 to this task. He worries,

How does the well-functioning approach avoid what Broome sought unsuccessfully to avoid [validating Schema Detach]? That is far from obvious [19].

The problem is that in order to avoid validating Schema Detach, Raz needs more than that his account of instrumental reason doesn't directly appeal

${ }^{6}$ In particular, as Raz notes [note 17], we need to distinguish between actions which properly count as ways of doing $A$ and other actions that necessarily follow from doing $A$, but are not ways of doing it: paradigmatically, doing A or B. This is a distinction that those who are willing to employ only purely logical properties of actions are going to have a hard time acknowledging. But it is a mild sort of metaphysics to recognize that if $\mathrm{X}$ does $\mathrm{A}$, and hence does A or B, it is true that she does A or B only because or in virtue of the fact that she does A. So I don't think this should give proponents of the Facilitative Principle pause. 
to the kind of reason that Wide Scopers appeal to. He needs to show that there is no such reason.

But his argument for this in section 3 is fairly peculiar. He assumes that if there is any such reason, it must derive, as is claimed by, for example, Wallace, 7 from a reason not to have contradictory beliefs. And so what he tries to show in section 3 is that there is no distinctive reason not to have contradictory beliefs. This is distinctly odd, since one might think that this is only one proposal for what might explain a reason to either take the means to your ends or not have those ends. ${ }^{8}$ Even so, his argument that there is no such reason is unconvincing, turning on the idea that the only thing that could be wrong about having contradictory beliefs is that it guarantees that at least one is false.

But just as it's not at all obvious that the only thing wrong with failing to take the means to your ends is that it involves believing a contradiction, it's not at all obvious that believing something false is the only thing wrong with having contradictory beliefs. If someone insists to me that she believes that $p$, and that if $p$ then $q$, but also that $\sim q$, then, other things being equal, I will suspect that there is something worse going on than that she has at least one false belief. Raz is clearly right that the logical paradoxes show that it is clearly rationally permissible to continue to believe things that we know to be in conflict [20], but it is far from showing that there are no reasons to withhold belief on these topics. The logical paradoxes make a good case precisely because there are so many other reasons why it is hard to get by, withholding belief on all of the implicated topics. This is one place where Raz's argument seems to trade on switching back and forth between discussion of reasons and discussion of rationality. ${ }^{9}$

So we should find Raz's arguments on this score unconvincing. In order to show that his account does not validate Schema D etach, Raz needs to do more than to show that he does not directly appeal to the Wide Scopers' reason. And he needs to do more than to show that there is no distinctive reason not to have contradictory beliefs. He needs to demonstrate that there is

\footnotetext{
7 Wallace [2001].

8 Compare, for example Bratman [unpublished], who calls this kind of explanation of the norms governing instrumental reason "cognitivism," and argues persuasively that it is unsuccessful. Compare also the criticism of Wallace in Brunero [2005], published along with Raz's paper.

9 Another important such place is in section 5, when Raz claims that "[w]henever reasons both (a) can bear on the case for and against one and the same action or attitude, and (b) can conflict, they can feature inseparably in the same arguments, and in the same deliberative processes, and therefore share in the same form of practical irrationality" [25]. This seems to be the real lynchpin of his argument that there is no distinctive domain of instrumental reason. But again, it depends on what you mean by saying that there is no distinctive such domain. O bviously it shows that there is no domain of reasons that cannot be, at least in principle, weighed against other reasons. But it doesn't show that there isn't a distinctive sourœ of some reasons - instrumental ones - or that reasons from such a source aren't simpler or easier to understand.
} 
no reason whatsoever to function properly. For, on Raz's account, cases in which an agent has an end and does not take the necessary means are all cases of improper cognitive function. So if there were any reason at all to function properly, then surely it would follow that there is a reason to either take the means to your ends or else give them up, because this is a way of functioning properly. And so it would follow, by the Facilitative Principle, that if you have the end, then there is a reason for you to take the means.

That there must be some such reason to function properly, I think it is hard to deny. Raz calls proper functioning an ideal, and claims that its being an ideal is not due to its consequences. This is what he says about goods on page 3. But Raz holds that the value of these things is a reason to engage in and to respect them. And even if Raz denies that there is anything whatsoever that is valuable about proper functioning (even though he himself calls it an "ideal"), and denies that what makes it an ideal is its consequences, it still seems unlikely that proper cognitive functioning will in general fail to have any good consequences of the kind that would lead to a reason to function properly. Y et, if there is any such reason, then it would seem that Raz's view validates Schema D etach. This, I think, should make us start to wonder why it is so obvious that invalidating Schema D etach is a constraint on an adequate account of instrumental reason, and in a serious way.

\section{The Argument Against Schema Detach}

Raz's argument against the validity of Schema D etach is the standard, obvious one - by counterexample. In cases in which someone's ends are deeply immoral or irrational - for example, that of counting the blades of grass on the White House lawn, or of becoming the world's most prolific axe-murderer - it does not seem to follow from the fact that the agent has such an end that there is a reason for her to take the means to it. It seems that there is no reason for aspiring grass-blade-counters to count blades of grass, and it seems that there is no reason for aspiring axe-murderers to sharpen their blades and practice their swings. So it seems that Schema Detach must be invalid.

Raz insists throughout, however, on formulating the issue by describing the validity of Schema D etach in a very particular way. He insists on describing the validity of Schema D etach as the claim that ends are reasons to take the means [10], or that they provide or give reasons to take the means [13]. In fact, in arguing that Wide Scopers are committed to Schema D etach, he takes great care to insist not only that they are committed to the view that if you have an end then there is a reason for you to take the means, but that

it is not only natural, but also true and not misleading to say that the intention gives one a reason to pursue the means to its fulfillment. ${ }^{10}$

10 Raz [2005, 13], italics added for emphasis. 
To say that Schema Detach is valid but intentions themselves are not reasons, Raz contends, "seems like hair splitting" [12].

O ne might be suspicious about why it is so important to Raz to insist on describing the validity of Schema $D$ etach by saying that ends are or provide reasons, if that is really no more misleading a way of describing the view than by simply describing Schema Detach and saying that it is valid. If his clear intuitions that it is not valid don't turn in any way on describing this thesis by saying that ends provide reasons, then why is it so important to his argument to describe it in that way? I'll now argue that intuitions to the effect that there is no reason for the aspiring grass-blade-counter to count her blades of grass are of a form that we should predict on general methodological grounds to be potentially systematically misleading. And in the process we'll see why describing the case in the way that Raz does is even more misleading. The moral of this section will be that it should not be obvious that Schema D etach is not valid. Then, in section 4, I'll summarize some of the reasons for suspecting that it might be valid after all.

O ur intuitions about the proposed counterexamples to Schema Detach are suspicious in virtue of their form. They are intuitions to the effect that there is no reason to do something. But all such intuitions should be suspect on general pragmatic grounds. For perfectly general pragmatic principles predict that sentences like "there is a reason for X to do A " will sound false even if there is a reason for $X$ to do A, so long as that reason is sufficiently weak. There are two parts to this prediction.

First, note that reasons have different weights or strengths. Some are weightier than others. And if the point of talking about reasons is ultimately to be able to use them in deliberation, it will therefore be the weightier reasons in which we are most interested. If I say that $R$ is a reason for you to do A , it is natural for you to assume that I mean to convey that it is at least a weighty enough reason for you to pay attention to in your deliberations about whether or not to do A. But it is plausible that not all reasons share this feature. A list made by God of all of the pros and cons of your action might be infinitely long, and if so, it will only be worthwhile paying attention to the top of the list. Or it could be that the reason for you not to do A is so conclusive and obvious that it is not even worth bothering with reasons to do A , which will never outweigh it, anyway. In cases like these, you have reasons that are not weighty enough to be worth paying attention to in your deliberations. But in ordinary contexts, when I say that R is a reason for you to do A, you will naturally understand me as trying to convey that it is not like this. And this follows simply from the fact that in ordinary contexts, we are ultimately interested in reasons in order to place weight on them in our deliberations.

But we can make a second important pragmatic prediction. This is that if instead of saying that $\mathrm{R}$ is a reason for you to do A , I say only that there is a reason for you to do A, the presumption that I have a relatively weighty reason in mind will be reinforced. This is because relative to weighty reasons, 
weak or poor reasons must be relatively more common. $\mathrm{M}$ ost of the reasons on God's infinite list of pros and cons aren't worth bothering with in your deliberations. Likewise, there are more actions in favor of which there is at least some reason, than actions in favor of which there is a particularly weighty one. The more actions in favor of which there is at least some reason, the more uninformative it is to say that there is at least some reason in favor of them. So it follows from Grice's maxim of quantity ${ }^{11}$ that my saying only that there is a reason for you to do A , but not saying what it is, should reinforce the presumption that I only have relatively weighty reasons in mind.

This gives us two independent predictions. If there is some action in favor of which there are only relatively weak or poor reasons, and I tell you that there is a reason to do it, you will find this unintuitive or false. And this is because you will naturally understand me as committed to claiming that it is a relatively weighty reason. If I go on to tell you what the reason is, the ex tra presumption that I must have a relatively weighty reason in mind will go away, and so you should find what I say less unintuitive. But you should still find it unintuitive. And then if I make clear that I don't mean to say that it is a relatively weighty reason at all - but in fact think that it is quite a weak or poor reason - then the unintuitiveness of what I say should go down a second time.

And it is easy to bear out these predictions. I think that you have a reason to eat your car.12 That sounds obviously false. But I haven't told you, yet, what I think it is. I think that it is that your car contains the recommended daily allowance of iron. Now what I say sounds slightly less insane - not uncrazy, to be sure, but slightly less insane. After all, if anything is a reason for you to eat your car, surely this is it. But now I go on. Truth be told, although I believe that this is a reason for you to eat your car, I don't think that it is a particularly weighty one. Indeed, I think that it is particularly poor - about as poor as reasons can get. Not only do I not think that you should place much weight on it in your deliberations, neither do I think that you should place any weight on it at all - in fact, I don't even think that you should deliberate about whether to eat your car in the first place. The reasons not to do it are so much better than the reasons to do it that you would be irrational if the question even came up, for you. I take it that my assertion that there is a reason for you to eat your car now sounds at least somewhat more reasonable, confirming our predictions.

So general pragmatic principles should make us suspicious about intuitions to the effect that there is no reason for someone to do something. They make empirical, verifiable predictions, which are borne out by investigation. But it follows from the pragmatic argument that these intuitions would be on better footing, if we knew what the reason for the aspiring grass-bladecounter to seek security clearance at the White House is supposed to be. This

11 "Make your contribution as informative as is required" [1967, 26].

12 As Adam Elga first pointed out to me. 
is why, I think, Raz is so careful to insist that, according to the detaching view, it is intentions that are or provide reasons. It is supposed to be obvious that these are not reasons. But unfortunately for this argument, nothing about the validity of Schema Detach tells us what the reason for the blade-counter to seek White House security clearance is. So if we are looking for a general argument that Schema D etach is invalid, it will have to trade on our intuition that there is no reason for her to do so, an intuition about which I've argued that we should be very cautious.

\section{Validating Schema Detach}

Not only should we find the arguments that Schema Detach is invalid suspicious, but there are also more reasons than Raz notes to suspect that it is true. Not the least of these is Raz's argument. If Raz is right about the Facilitative Principle, then avoiding validating Schema Detach is going to be hard. Even Raz's own view, or at least so I've argued, will not succeed. If Raz is right about the Facilitative Principle and I am right about the pragmatic considerations from section 3, then perhaps this is simply not so bad. Perhaps it is a result that we should simply embrace and learn to live with.

But there are also more general reasons to like Schema D etach - so long as the unintuitive reasons it results in turn out to not be very weighty.13 For example, Schema D etach postulates a clear asymmetry between taking the means to your ends, and giving the end up. And importantly, there should be some such asymmetry, which Wide Scopers don't explain and it is unclear how Raz's view explains. It is true that someone who gives up her end rather than taking the means is, so to speak, rationally "in the clear." She has achieved a state in which there is no end to which she is not taking the means. Similarly, if she takes the means to the end that she has, she achieves a state in which she is rationally in the clear. But these are very different ways of becoming rationally in the clear. The latter seems to involve satisfying the rational pressure to take the means, but the former seems only to involve escaping it. Similarly, though you are "in the clear" if you get the person to whom you have made a promise to excuse you, this is not so much a way of satisfying your promise as of escaping it. Schema D etach can explain what is going on in the domain of instrumental reason in a way that gets asymmetries like this one right and, in doing so, explains them. ${ }^{14}$

Another motivation for accepting Schema D etach, or at least something like it, has to do with what kind of ex planation we are going to be able to give for the norms invoked by our account of instrumental reason. If we use something like Schema Detach to give our account, then explanations of these norms will be able to make use of rich resources - for every reason to be explained, there is an end on hand to play a role in helping to explain it. This is why, Kant says, explaining the possibility of hypothetical imperatives

13 For more on the weight of such reasons, see Schroeder [forthcoming].

14 See Schroeder [2004] for further discussion. 
is easier than explaining the possibility of a categorical imperative - for hypothetical imperatives, like the reasons to which Schema D etach is committed are "based on a presupposition," which can be used to explain them.15 But the reason appealed to by Wide Scopers is not based on any presupposition it is not contingent on any feature of the agents for whom it is a reason, since it is a reason for everyone, no matter what she is like. Similarly, the "ideal" of proper functioning to which Raz appeals is not based on any presupposition about the agents for whom it is an ideal. So this leaves Raz and the Wide Scopers with fewer resources with which to be able to explain these things. And that is, again, an intelligible motivation for wondering whether Schema D etach might be valid, after all.16

A final consideration in favor of the validity of Schema Detach derives from consideration of the case of undercutting defeaters. The classic cases of undercutting defeaters come from epistemology, and one goes something like this:17 Y ou see Tom G rabit come out of the library, pull a book from beneath his shirt, and cackle gleefully, before running off. This gives you some reason to believe that Tom stole a book from the library. But now suppose that Tom has a twin brother, Tim, from whom you cannot visually distinguish him at this distance. If so, then your visual evidence is not such a good reason to believe that Tom stole a book after all. So the fact that Tom has a twin brother is an undercutter for your reason to believe that Tom stole a book. But importantly, it does not make it the case that you have no reason to believe that Tom stole a book. For if it turns out that Tom and Tim have a third identical sibling, Tam, then your visual evidence would turn out to be a still worse reason to believe that Tom stole a book. So it can't have gone away entirely. It has only been partially undercut.

Partial undercutters are a novel case, one not usually thought about.18 According to standard definitions of undercutting defeat, undercutters make it the case that some other consideration is not a reason at all.19 And some undercutters do seem, intuitively, to work in this way. For example, instead of supposing that Tom has a twin, suppose that after seeing him, you look up and see a movie camera and lights, and hear a director say, "Cut! One more take, Tom." Given this, your visual experience seems intuitively not to be a reason to believe that Tom stole a book at all. So in addition to partial undercutters, there are complete undercutters.

According to a natural hypothesis, complete undercutters and partial undercutters are not deeply different phenomena. On the contrary, complete undercutters seem simply to be like a limiting case of a spectrum of partial

15 Kant, G roundwork [4:419]. See Schroeder [2005] for further discussion.

${ }_{16}$ See, again, Schroeder [2004] for further discussion.

${ }^{17}$ Lehrer and Paxson [1969].

18 Jonathan Dancy is one of the only ones to discuss them. See Dancy [2005], chapter 2. D ancy also makes much of the analogy between undercutters in the epistemic and practical domains.

${ }_{19}$ Pollack [1986, 38-39]. 
undercutters we can construct by imagining that Tom has arbitrarily many identical siblings. ${ }^{20}$ If they are, then it would turn out that in cases of complete undercutting, there really is a reason present - but it is a limiting case of low weight. But given our earlier pragmatic considerations, that should hardly be a problematic result. For the pragmatic considerations predict that we will have the intuition that there is no such reason in precisely these cases - cases in which the reason is of little or minimal weight.

So if the fact that an end is immoral or irrational is a complete undercutter for reasons to take the means, then on a natural, well-motivated view, it would turn out that Schema D etach is valid. Raz's paper, I've tried to suggest, should be read as a defensive action in the struggle to insist that it is not. But if what I've argued in part 2 is correct, then Raz's defensive action fails. If what I've argued in part 3 is correct, then this should not make us overly anxious, anyway. And if what I've argued in part 4 is correct, then instrumental reasons really may be instrumental after all - not just in the sense of deriving from ends, but instrumental in allowing us to give a theoretically satisfying treatment of the domain, and of reasons in general.

For myself, I don't really know what to think about ends if they are understood as intentions. If Raz is really interested in instrumental reason in the same sense as it has been claimed that all reasons are instrumental, then in my view, the interesting question is not about intentions at all, but about desires. At least, properly understood, that is the sense in which I myself believe that all reasons are instrumental. ${ }^{21}$ But either way, I think we should be highly cautious about claims that there are no reasons to take the means. Reasons, as Raz notes in his argument for his view about the Facilitative Principle [9], are easier to come by than it is sometimes thought.22

Mark Schroeder

University of Maryland

mschroed@umd.edu

\section{References}

Bratman, Michael [1987]. Intention, Plans, and Pradical Reason. Chicago: University of Chicago Press. [unpublished]. "Intention, Belief, Practical, Theoretical." Unpublished paper. Presented at College Park Conference on Practical Rationality and The Unity of Reason conference at St. Andrews.

Broome, John [1999]. "Normative Requirements." Ratio 12(4): 398-419.

20 Oddly, D ancy himself suggests something like this, even though his central argument for particularism turns, like Raz's argument, on intuitions about what is not a reason [2005, 42].

21 See Schroeder [forthcoming], [unpublished].

22 Special thanks to Andrei Marmor and Joshua Knobe. 
[2002]. "Practical Reasoning." In Bermudez and Millar, eds., Reason and N ature: E ssays in the Theory of Rationality. Oxford: O xford University Press, 85-111.

Brunero, John [2005]. "Two Approaches to Instrumental Rationality and Belief Consistency." Journal of E thics and Social Philosophy, www.jesp.org, 1(1): 2-20.

D ancy, Jonathan [2005]. E thics W ithout Priniples. O xford: Oxford University Press.

D arwall, Stephen [1983]. Impartial Reason. Ithaca: Cornell University Press.

Gensler, Harry [1985]. "Ethical Consistency Principles." Philosophical Q uarterly. 35(139): 156170.

Greenspan, Patricia [1975]. "Conditional Oughts and Hypothetical Imperatives." The Journal of Philosophy. 72(10): 259-276.

Grice, H.P. [1967]. "Logic and Conversation." Printed in his Studies in the Way of W ords, Cambridge: Harvard University Press, 1989, 1-144.

Hampton, Jean [1998]. The A uthority of Reason. Cambridge: Cambridge University Press.

Hill, Thomas [1973]. “The Hypothetical Imperative." The Philosophical Review 82(4): 429-450.

Kant, Immanuel [1993]. G rounding for the M etaphysics of M orals. Trans. James Ellington. Indianapolis: Hackett Publishing Company.

Korsgaard, Christine [1997]. "The Normativity of Instrumental Reason." In Cullity and G aut, eds., E thics and Practical Reason. Oxford: O xford University Press.

Lehrer, Keith, and Thomas Paxson, Jr. [1969]. "Knowledge: Undefeated Justified True Belief," The Journal of Philosophy 66(8): 225-237.

Pollack, John [1986]. Contemporary Theories of Knowledge. Savage, Maryland: Rowman and Littlefield.

Raz, Joseph [2005]. "The Myth of Instrumental Reason." Journal of E thics and Social Philosophy, www.jesp.org, 1(1): 2-28.

Schroeder, Mark [2004]. "The Scope of Instrumental Reason." Philosophical Perspectives 18 (Ethics): 337-364. [2005]. "The Hypothetical Imperative?" A ustralasian Journal of Philosophy 83(3): 357372. [forthcoming]. "Weighting for a Plausible Humean Theory of Reasons." Forthcoming in $\mathrm{N}$ oûs. [unpublished]. Slaves of the Passions. Unpublished book manuscript. Under revisions for Oxford University Press.

Wallace, Jay [2001]. "Normativity, Commitment, and Instrumental Reason." The Philosophers' Imprint 1(3), www.philsophersimprint.org/ 001003/. 